\title{
Interferências da subjetividade estrangeira na tradução americana de Diário de Bitita, de Carolina Maria de Jesus
}

\author{
Raffaela Andréa Fernandez e \\ Sueli Meira Liebig
}

\begin{abstract}
RESUMO
Este artigo empreende um estudo comparatista entre a versão brasileira de Diário de Bitita, de Carolina Maria de Jesus e sua tradução para o inglês americano feita por Emanuelle Oliveira e Beth Joan Vinkler, intitulada Bitita's Diary: the childhood memoires of Carolina Maria de Jesus. As versões analisadas são baseadas na edição original francesa da obra, primeira versão póstuma publicada pela jornalista e editora A. M. Métaillié, que teve acesso aos manuscritos antes da morte de Carolina e os publicou em 1982. O romance só viria a público no Brasil em 1986, quatro anos após essa primeira tirada europeia, quando teve os direitos de edição em língua portuguesa adquiridos pela Editora Nova Fronteira. O nosso intuito neste estudo é observar em que medida a subjetividade das tradutoras da obra para a língua inglesa produziu efeitos de sentido e de que maneira essas possíveis interferências podem vir a afetar o leitor. Procuramos ainda refletir se as modificações realizadas podem incidir sobre os leitores na absorção desses novos sentidos gerados pela retextualização. Para tanto, baseamo-nos nos estudos de Rosemary Arrojo; Jacqueline Authier-Revuz; Rodrigues; Venuti; Neuza Gonçalves Travaglia, Paul Ricoeur e Germana Souza.
\end{abstract}

Palavras-chave: Carolina Maria de Jesus. Tradução. Interferência. Subjetividade..

\section{Introdução}

Como leitores, sempre preferimos o texto "original", se assim podemos chamar um texto que gera uma tradução para uma língua e, consequentemente, para uma cultura diferente. Resistimos não só ao texto secundário, mas à própria ideia do texto estrangeiro. Se não há escapatória, como lembra o doublé de diplomata e jornalista Eduardo Ferreira (2014), nos voltamos para a tradução "domesticadora",

* Universidade de Campinas - UNICAMP

** Universidade Estadual da Paraíba - UEPB 
aquela que apaga ao máximo a marca do estrangeiro apropriando-se do texto alheio, para torná-lo "nacional". De acordo com Ferreira,

A suposição de intraduzibilidade é real e devidamente motivada. Como traduzir literaturas forjadas em línguas cujas sintaxes não se ajustam, cujos vocabulários não se encaixam, cujos ritmos pulsam em cadências assíncronas, cujos signos remetem a imagens que parecem desencontrar-se? Pior: como traduzir se o humor que flutua sobre o texto, nos entremeios do texto - lubrificando com frouxos sentidos o espaço entre as palavras - não encontra eco na língua de chegada? (FERREIRA, 2014, p. 1).

Assim, no trabalho de tradução, a construção do comparável não se encerra com a supremacia da identidade, mas com a efêmera produção de semelhanças ou correspondências inadequadas. Como acontece com a poesia, a tradução preenche a vontade de potencializar a língua pela descoberta dos seus recursos ainda não investigados quando da apresentação do pensamento. Reportando-se à questão da lealdade à obra traduzida, Patrícia Lavelle, no prefácio de Sobre a tradução (2011) $)^{1}$, assim sintetiza o pensamento de Paul Ricoeur:

Ricoeur procura substituir o clássico dilema do intraduzível e do traduzível por uma alternativa prática: fidelidade versus traição. Nesse sentido, ele deixa de lado uma certa filosofia da tradução que oscila entre a tese da sua impossibilidade teórica e a constatação de sua prática efetiva, para pensá-la como elaboração de "correspondências sem adequação", de "equivalências sem identidade", ou seja, como uma resposta construtiva ao desafio representado pela diversidade das línguas (LAVELLE, 2011, p.78 - destaques da autora).

Da mesma forma, vários teóricos esboçam suas teorias textuais defendendo a impossibilidade de uma total recuperação de valores puros quando um texto passa por um processo tradutório. (STEINER, 1975; FISH, 1980; DERRIDA, 2000; QUINE [1960] 2013). Esta visão pós-estruturalista defende a elaboração de

1 Sobre a tradução (2011) é o título da tradução para o português brasileiro do livro Sur la traduction (2004), de Paul Ricoeur, feita por Patrícia Lavelle. A obra é a compilação de três ensaios relativamente curtos, mas bastante profundos. No prefácio da tradução, Lavelle faz uma excelente abordagem crítica do texto de Ricoeur, resumindo o pensamento do autor sobre o ato de traduzir ao pinçar os principais conceitos do livro. 
uma tradução atribuída à constituição de significados formados com base em uma interconexão de diferenças, onde os valores são constituídos como uma função produzida pelo sujeito, de acordo com convenções socioculturais peculiares a determinadas comunidades. A análise que desenvolvemos neste estudo certamente toma essas questões em consideração, mas se preocupa fundamentalmente com o problema da interferência da subjetividade das tradutoras sobre a obra, uma vez que ela é produto da versão francesa dos manuscritos de Carolina, que por sua vez foram (re)traduzidos para o português e a partir da versão brasileira vertidos para a íngua inglesa, produzindo uma linguagem em abismo.

A obra Diário de Bitita, de Carolina Maria de Jesus ${ }^{2}$ foi publicada no Brasil em 1986, mas primeiramente editada na França sob o título de Journal de Bitita, em 1982. Tomamos como objeto de estudo neste trabalho a tradução da versão brasileira para o inglês norte-americano, realizada por Emanuelle Oliveira e Beth Joan Vinkler, em 1998, com o título Bitita's diary: The childhood memories of Carolina Maria de Jesus, a fim de observarmos a existência de interferências da subjetividade das tradutoras no texto final, a partir dos próprios títulos dos capítulos, que, por conseguinte, modificam o sentido da escrita de Carolina, principalmente no que concerne ao estilo oralizado que caracteriza o processo criativo da autora.

Como observa Germana de Souza no artigo "A tradução francesa da linguagem compósita de Carolina Maria de Jesus", a linguagem fragmentada de Carolina sofre uma ruptura na tradução francesa Le dépotoir (1962) verificada quando a cotejamos com a publicação de Quarto de despejo:

A verbalização em francês desse contexto é feita por meio de uma linguagem sem relevo, homogênea, que ignora as fraturas da linguagem de Carolina de Jesus. Com efeito, Canto tenta encontrar modelos já prontos para o texto traduzido, adapta o texto estrangeiro às normas de tradução já existentes, como se pode ver nos textos de acompanhamento da obra traduzida. A quarta capa da primeira edição de Le dépotoir apresenta um texto sem assinatura, que devemos sem dúvida atribuir ao editor, no qual é feita uma aproximação

2 Carolina Maria de Jesus foi uma catadora de lixo, moradora da favela do Canindé, em São Paulo, que em 1960 conseguiu publicar seu livro intitulado Quarto de despejo. O sucesso editorial marcou este acontecimento, mas em pouco tempo a "poeta do lixo" logo viria a cair no esquecimento. Em 1961, os mesmos editores do primeiro livro de Carolina, Audálio Dantas e a editora Francisco Alves, publicaram o que seria a continuação dessa obra, Casa de Alvenaria. A autora publicaria ainda em vida No sítio (1962), Pedaços da fome (1963) e Provérbios (?). Em 1980 os manuscritos de Carolina foram adquiridos pela editora francesa A. M. Métaillié, que os publicou em 1982. A obra foi traduzida pra o português em 1986, pela editora Nova Fronteira e finalmente vertida pra o inglês em 1988, que é a versão analisada nesse artigo. 
entre o diário caroliniano e a obra de Anne Frank: "C'est aussi que Le dépotoir est un livre exceptionnel, un témoignage d'un intérêt humain aussi indiscutable que a journal d'Anne Frank par exemple" (SOUZA, 2011, p. 127).

Interessante notar que na tradução para o inglês a capa também apresenta um texto sem assinatura, de modo que lemos a firma do editor Robert M. Levine em destaque e logo abaixo os nomes das tradutoras. A autora é citada apenas no subtítulo: Bitita's diary: the childhood memoires of Carolina Maria de Jesus, ficando evidente que a obra de Carolina é relegada ao status de mero testemunho, sem qualquer valor literário, assim como na versão francesa. Mais adiante iremos observar alguns momentos em que essa visão sensacionalista da autobiografia de uma mulher favelada, perpassa o processo de tradução e desconstrói as particularidades literárias da escrita caroliniana ${ }^{3}$.

Como observa Fernandez (2006) a poética de resíduos realizada por Carolina é entrecruzada por diversos discursos nutridos por fragmentos da linguagem popular vivenciada por ela, bem como pela captura da linguagem culta adquirida dos livros e jornais lidos como autodidata e inserida em seus textos. Assim como Souza (SOUZA, 2011, p. 127), notamos que essa característica superimportante sofre ajustes por vezes gratuitos na retextualização.

Nesta análise procuramos ainda refletir em que medida as modificações realizadas poderiam incidir sobre os leitores na absorção desses novos sentidos gerados pela retextualização. Para tanto, seguimos as pegadas de Travaglia, que leva em consideração o que chama de "arranjo de marcadores",

papel que certamente não pode ser negado ao texto enquanto instrumento de interação e colocador de possibilidades de sentido através de sua materialidade, enquanto "arranjo de marcadores"./ Não podemos esquecer que a leitura de um texto não é absolutamente livre e independente. Está sujeita a contingência, regras e princípios estabelecidos pela própria língua e que de certa forma estão impressos nas marcas que formam o texto. É o "arranjo de marcadores" tal como está que, combinado com toda a experiência do leitor, provoca construção de sentidos. (TRAVAGLIA, 2003, p. 55).

3 Como nos lembra Maria José Coracini, falar sobre si não garante a subjetividade de si, tampouco falar do outro possibilita qualquer objetividade, pois qualquer discurso, de algum modo, é construção de "uma história, uma narrativa, uma ficção que se torna, pela discursividade, uma verdade, melhor dizendo, uma realidade" (CORACINI, 2007, p. 117). 
Através dos apontamentos delineados no item seguinte, veremos como os significados da versão brasileira traduzida sofreram modificações pelas leitoras/ tradutoras. Esse mecanismo como produto de interação, como nos lembra Travaglia (2003), soma-se à interação subjetiva dos demais leitores. Para a autora, o novo texto produzido pelo tradutor ganhará efeitos de sentido para os leitores, o que demonstra serem importantes todos os fatores de textualidade, e não somente os códigos linguísticos envolvidos na tradução, como é o caso, por exemplo, da linguagem oralizada de Carolina, ou da sua escrita compósita que passam despercebidas às tradutoras e que farão toda a diferença na produção de efeito de sentidos.

\section{Transposição, dissociação e interpretação dos sentidos}

O sentido de um texto nunca é imobilizado uma vez que ele se produz nas situações dialógicas ilimitadas constituídas por suas leituras possíveis: pensa-se evidentemente na "leitura possível". (AUTHIER).

Na tradução brasileira, temos no capítulo I, denominado "Infância", a seguinte passagem: "Nós morávamos num terreno que vovô comprou 'do mestre, um professor'4 que tinha uma escola privada" (JESUS, 1986, p.7). Já em Bitita's diary, no capítulo III, temos: "We lived on a land that grandpa bought from a 'man known as the teacher"' (JESUS, 1998, p. 3). No livro de Carolina, ela diz que a pessoa de quem o avô dela comprou o terreno era um professor, mas na tradução esta pessoa não era um professor, mas alguém conhecido como "professor". Como vemos, há um rebaixamento da posição intelectual do professor citado por Carolina como um mestre. Ao utilizar a expressão "a man known as the teacher", isto é, "um homem conhecido como professor", as tradutoras ignoram a valorização que Carolina atribui a essa figura. É importante destacar essa modificação, pois Carolina possuía grande afeto e admiração às pessoas ligadas à educação, como podemos confirmar no capitulo XI, intitulado "A escola". No entanto, a exemplo do pensamento de Authier, podemos imaginar os entraves da "leitura possível" das tradutoras marcadas pelo olhar estrangeiro sobre as obras de Carolina, que inclusive, muitas vezes pode até despertar interesse ou equívocos nas classes mais abastadas, mesmo no Brasil.

4 Grifo nosso que estará presente em todo texto com a finalidade de sublinhar as principais mudanças lexicais dos excertos selecionados para análise. 
O capitulo III de Diário de Bitita é nomeado de "A festa", mas na reescritura das autoras foi transformada em "Holiday", que significa "feriado" na língua inglesa, ao invés de "Party", que significa "festa", e poderia ser a tradução mais próxima ao título. O fato não nos passa despercebido uma vez que podemos pensar nos possíveis efeitos de sentido provocados no leitor. Se atentarmos para o fato de que um feriado não necessariamente é uma festa, isso denota uma mudança de sentido fundamental, uma vez que o leitor poderia vir a entender que haveria festa em todos os feriados brasileiros, reforçando o estereótipo do Brasil como um "país do carnaval", enquanto que ao contrário, Carolina questiona e crítica as convenções sociais das comemorações do ano novo e do carnaval:

Às vezes eu notava as agitações do povo comprando tecidos para confeccionar vestidos para usar no dia do ano-novo. Por que será que todos falam e sorriem neste dia? E estes dias eram com bailes. Quem será que inventou o baile? Mas eu notava que o dia do anonovo era igual os outros com as suas misérias e angústias./ Depois do ano novo era o carnaval. Então o mundo é sempre assim? Todos os anos é a mesma coisa? Minha mãe disse que não. (JESUS, 1986, p. 22).

Ainda nos mesmos capítulos referentes a esse tema - "A festa" -, observamos a troca da preposição "do" por "With" ("com"em inglês) que muda o sentido, e consequentemente, a lógica do leitor que geralmente vê a tradução como um original, já que muitas vezes não conhece a língua de partida. Vejamos como isso acontece: "Tinha hora que eu tinha um medo do mundo! Era quando ouvia os homens falarem nas dificuldades para um homem encontrar trabalho. O mundo não é um paraíso para o homem. A guerra 'do' Paraguai foi trágica (...)”. (JESUS, 1986, p. 23). Na tradução lemos: "There were times when I was so afraid of the world! it was when I heard men talking about how hard it was for a man to find work. The world isn't a paradise for man. The war with Paraguay was tragic". (JESUS, 1998, p. 15). Seria mantida a mesma estrutura, caso as autoras tivessem optado pela seguinte retextualização: "The war of Paraguay was tragic". Nesse caso, o leitor não perderia o conteúdo original, pois da maneira como foi traduzido não sabemos se a guerra foi do Brasil com o Paraguai, do Brasil junto com o Paraguai ou o mundo todo contra o Paraguai. Seria necessário inferir que o leitor já conhecesse a história do Brasil e soubesse que essa guerra foi entre o Brasil e o Paraguai, e que os negros "livres" foram enviados a força para os campos de 
batalha como barricada para o exército branco. ${ }^{5}$

Mais adiante nota-se uma falha no sentido do verbo escolhido para a retextualização da expressão 'Uma mulher 'havia mandado' um rei cortar a cabeça de Sâo João Batista”. (JESUS, 1986, p. 33): “A woman 'had made' a king slay off Saint John The Baptist's head" (JESUS, 1998, p. 15). O verbo "mandar" conjugado no mais que perfeito como "havia mandado" transforma o sentido da frase. Na versão de Carolina, o verbo significa uma ação que não é obrigatória, mas quando essa locução verbal é empregada em língua inglesa, sua carga semântica se intensifica a ponto de expressar uma obrigação. Em suma: no português, a fala é mais sutil e não temos certeza da ação, enquanto que, em inglês, o verbo indica uma ação fechada, incondicional, na qual não há dúvidas de que o rei ordenaria o homicídio de João Batista. Em outro momento ocorre novamente uma mudança de significação da ação devido à troca de verbos e de substantivos: "Passados uns dias, 'resolvi' entrar no 'quintal' da vizinha”. (JESUS, 1986, p. 54). Abaixo vemos a substituição do verbo "resolvi” por "decided" (decidi) que transforma totalmente o contexto da ação. Na publicação brasileira, o verbo "resolver" nos dá a ideia de algo realizado, ou seja, a personagem entrou no quintal, enquanto que na tradução ela "decidiu", ou seja, refletiu sobre uma entrada que pode não ter se realizado. Em ambas as passagens acima citadas, observamos que as modificações dos verbos transformam a linguagem incisiva de Carolina, marcada pela crítica radical, aquela que não titubeia ao recontar suas memórias e as unir a outros fatos, argumentos ou mitos como no caso da rememoração da presença inefável da personagem bíblica Salomé.

Estas escolhas podem nos induzir a pensar que as tradutoras amenizam o tom da contundente linguagem empregada por Carolina, mascarando a sua personalidade e a deslocando para o lugar da gente humilde da favela brasileira, povo sofrido, passivo, afônico. Imagem bastante difundida pela mídia enquanto a autora esteve presente nas manchetes mundiais e no Brasil, sobretudo no Jornal do Brasil, como nos mostra Mário Silva, ela aparecia como a autora "inocente de um livro fantástico”. (SILVA, 2010, p. 4). Na cobertura da imprensa havia uma tentativa de registrar suas ações sob o signo da inocência simplória de uma autora tola, "produto de um acaso, ou fruto de um golpe publicitário, explorada ingenuamente". (SILVA, 2010, p. 9).

No capítulo VII, intitulado "Família", ocorre o fortalecimento da situação de miséria vivida pela protagonista. Nas palavras da Carolina, traduzida já para o 
francês, lemos: “As colheres para comer também 'eram de pau'”. (JESUS, 1986 p. 66). Na tradução inglesa do português, traduzido do francês, lemos: "The spoons she ate with 'were also wooden"'. (JESUS, 1998, p. 48). Na reescritura, a colher de pau descrita não nos leva a deduzir que ela seja um objeto talhado em madeira, podendo ser qualquer galho de árvore ou pedaço de pau encontrado e adaptado para substituir a falta de utensílios comuns. As tradutoras exageram ao pintar o quadro de miséria em que vivia a autora, demonstrando uma situação social quase primitiva, semelhante à vivida pelos índios brasileiros, uma imagem que percorre o imaginário dos estrangeiros leigos quando pensam no Brasil como um lugar exótico, habitado apenas por aborígenes e feras selvagens. Sabemos que literariamente esse mecanismo incrementa a leitura e causa comoção no leitor, envolvendo-o ainda mais na história de pobreza vivida por Carolina.

No trecho "Os grandes têm coragem de enfiar uma faca "no outro". (JESUS, 1986, p. 107) traduzido como "Grown-ups have the nerve to stick a knife "in one another" (JESUS, 1998, p. 78), ocorre uma mudança do referencial "no outro" para "in one another", que traduz-se "um no outro". Como vemos, em Carolina a ação não implica numa reação, pois o "outro" seria o pequeno, o negro, o pobre, em contraposição ao grande, o rico, o branco. Na tradução, o ataque pode ocorrer entre os "grandes". Desse modo, temos uma ação e uma reação. Houve nova mudança de sentido que descaracteriza o discurso crítico de Carolina em relação à luta das classes, em especial à condição desigual dos negros brasileiros, uma questão que está evidente no excerto abaixo:

_Não quero gente grande no mundo. São os grandes que são maus. As crianças brincam juntas, para elas não existe a cor. Não falam em guerras não fazem cadeias para prender ninguém./Eu não gosto dos grandes. Os grandes têm coragem de enfiar uma faca no outro. Outro dia um espinho entrou no meu pé e doeu tanto! E se fosse uma faca? O tio Cirineu me ouvia e dizia:/_Esta negrinha vai longe. (JESUS, 1986, p. 107).

À medida que avançamos na leitura da tradução, encontramos outros itens que levam a interpretações errôneas de sentido entre as versões do português brasileiro para o inglês americano: são diversas mudanças nos tempos verbais, como, por exemplo, a negação no tempo condicional "wouldn't receive" (não receberia) que entra no lugar do presente infinitivo afirmativo "receber": I cried because I 'wouldn't receive' my diploma for two more years (JESUS, 1998, p. 95) - "Chorei porque faltavam dois anos para eu 'receber' o meu diploma" 
(JESUS, 1986, p. 12). Desta maneira, a frase em português em que Carolina lamenta ter que sair da escola e deixar de receber o seu diploma faltando apenas dois anos para obtê-lo, transforma-se num pensamento diferente, o lamento por ter que esperar mais dois anos até conseguir obter o tão sonhado diploma. Além do mais, tal alteração interfere novamente no estilo de Carolina, que busca presentificar através da narrativa autobiográfica os acontecimentos vividos, pois a escrita no tempo presente perfaz o caminho da memória que revive os fatos ao narrá-la ${ }^{6}$.

Mais alterações verbais são percebidas na descrição do pensamento da comunidade em relação aos negros, quando Bitita é acusada injustamente de ter roubado cem mil réis de um padre, que, em seguida, quer pedir-lhe desculpas, mas “A família 'não consentiu' dizendo que o negro tem mentalidade de animal. A prova é visível, eles só sabem dançar e beber pinga. O padre disse que ia rezar, pedir a Deus que me ajudasse na vida". (JESUS, 1968, p. 144). Em Bityta's diary temos: "The family 'wouldn't permit it', saying that blacks have the minds of animals. The proof is evident, they only know how to dance and drink pinga. He said that he would pray to ask God to help me in life". (JESUS, 1986, p. 107).

Talvez possamos dizer que essa mudança verbal tente representar a mentalidade do outro ao optar por "wouldn't permit it" que significa "não permitiria isso". Parece que as tradutoras procuram expressar através do verbo no condicional os valores culturais da família pobre e negra de Carolina. Porém, na versão brasileira a autora afirma no passado acabado que sua família "não consentiu" que o padre lhe pedisse perdão. Como podemos notar pelo teor de toda a obra, este valor cultural de submissão do negro pobre em relação aos brancos faz parte da experiência de vida - aqui denunciada - da autora.

No capitulo XVII, nomeado "As leis da hospitalidade", observemos como a tradução oblitera a crítica de Carolina em relação à suposta "superioridade do branco". No trecho em português ela dispara:

A Marcelina estava noiva de um pretinho de nome Otávio. Pensei: "A tia Ana agora já mistura-se com os negros. O seu orgulho está enfraquecendo-se". E tive esperanças que ela me ajudasse. Que vontade de dormir!/

Chegou o José Marcelino. Não me cumprimentou. Olhou me com rancor. Pensei: "Que raça antipática!” (JESUS, 1986, p. 162).

6 Para maiores aprofundamentos consultar, Gomes (2004). 
Enquanto que, em Bitita's diary, temos uma mudança de sentido quando as tradutoras reduzem o todo (a raça branca) a uma só pessoa (João Marcelino, um indivíduo mau caráter), "a disagreable character", vejamos:

Marcelina was engaged to a young black man named Otávio. I thought, "So now Aunt Ana intermixes with blacks. Her pride is weakening". And I was hopeful that she would help me. How I felt like sleeping!/

José Marcelino arrived. He didn't greet me. He look at me with rancor. I thought,: "what a disagreeable character!"

(JESUS, 1998, p. 120).

Como podemos ver, a tradução gera um efeito de amenização do pensamento de Carolina para com a "raça branca". Sua fala expressa um descontentamento com seus familiares brancos, que não lhe dão a devida atenção. É sabido que nesse momento da história brasileira, era comum os brancos explicitarem seu sentimento de superioridade em relação ao negro, do mesmo modo como era comum os negros se submeterem aos brancos, como podemos ver acima. O leitor que jamais leu a obra em português pensaria que essa crítica recai sobre o caráter de uma pessoa, José Marcelino, filho de Ana, a tia branca e racista de Carolina. No entanto, quando a autora diz "Que raça antipática!", está se referindo a todo o segmento da "raça" branca de sua época. Ao longo de seu livro, Carolina critica o comportamento racista dos brancos, como aqueles que não participavam das festas dos negros e não respeitavam os filhos dos negros, ou seja, que segundo suas descrições possuíam um comportamento preconceituoso e até mesmo desumano.

Na sequência do mesmo capítulo de Diário de Bitita, acompanhamos os questionamentos de Carolina em relação à existência de Deus, ao papel da mulher, à convivência entre negros e brancos, a sua condição de pobreza, à educação, enfim, a todos os elementos que permeiam o mundo em torno si. No entanto, as tradutoras sempre transformam esse caráter questionador em afirmativas simplórias, retirando dele o teor de reflexão filosófica, o posicionamento político. Talvez essa dificuldade seja uma constante devido à utilização da linguagem popular ou de um cultismo passadista de Carolina, que obstaculiza a interpretação estrangeira, logo a tradução, como podemos ver a seguir:

Cheguei na casa de tia Ana, falei com a Marcelina, dizendo que havia visitado a Maria Rita.

- Credo! Aquela mulher não presta! Você não deveria ter 
encontrado lá./ A tia Ana disse:/

- Por que é que você não vai pedir esmolas?/

Assustei. Pedir esmolas na minha idade? Era horroroso. Pensei:

"Vou tentar! E seja que Deus quiser!"

Saí andando, olhando as casas, procurando uma para pedir. Quem está doente não pensa na morte./

"Eu quero sarar para trabalhar em qualquer coisa. Hei de ter a minha casa! Deus há de me auxiliar”.

(JESUS, 1986, p. 164 -165).

$\mathrm{Na}$ troca desse questionamento, colocado através do desejo e da prece, pela afirmação que é própria do verbo "have", ocorre uma perda de sentido na reformulação das tradutoras:

Aunt Ana said, "Why aren't you going to go out and beg". I was startled. Beg, at my age? It was horrifying. I thought: "I'm going to try! And may it be as God wills". I went out walking, looking at the houses, seeking one at which to beg. Whoever is sick doesn't think about death. "I want to get well so that I can do some kind of work. I'm going to have my own house! God will help me”.

(JESUS, 1998, p. 123).

A substituição do verbo "haver" em português pelo verbo "have" (ter) em inglês causa um efeito de dissonância linguística e uma quebra do elemento da dúvida. A dissonância ocorre devido à perda da oralidade presentificada no uso passadista do verbo haver, que, no texto de Carolina, tem a função de demonstrar um desejo e uma prece. O verbo haver citado pela autora no futuro como "hei de" parece ter o mesmo sentido de um desejo a ser realizado talvez com o auxílio divino. Já na tradução, temos uma afirmação em "I'm going to have my own house" (eu vou ter minha própria casa), que não poderia ser produzida pela autora no contexto de sua fala, uma vez que esta vivia em condições mínimas de sobrevivência. Sua família morava sempre em casas alugadas, "entrava numa casa e logo se mudava" para outra por causa do preço do aluguel. Ao final do livro, Carolina não conseguiu adquirir uma casa própria, como intencionava.

O mesmo ocorre no capítulo XXI do Diário de Bitita, quando um questionamento feito por Carolina novamente é transformado numa afirmação, perdendo o tom ambíguo tão característico da sua narrativa: 
Quando eu pedi a dona Fiica que queria ir embora, ela não apreciou e perguntou-me:/ - O que é que te faltando aqui? Fala o que você quer que eu soluciono./ Pensei: "Vou pedir lhe para comprar roupas para mim. Mas se ela comprar, terei que ficar com ela . Já estou cansada de viver em campo. Se fosse para eu morar nesta fazenda para plantar, aí sim. "Mas espero que Deus ainda vai me auxiliar. hei de ter terras para plantar. Hei de ter a vida que espero ter". (JESUS, 1986, p.191).

Na versão em português, vemos que a autora espera o auxílio divino, mas questiona sua condição material concreta, que segundo sua visão deveria ser diferente. Ao contrário disto, no capítulo XXI de Bitita's diary a tradução afirma a realização das condições materiais dela num futuro bem próximo e indubitável:

When I told Dona Fiica that I want to leave, she didn't appreciate it and asked me, "What is it that you're lacking here? Tell me what you want and I'll take care of it"./ I thought, "I' $\mathrm{m}$ going to ask her to buy me some clothes. But if she buys them, I'll have to stay with her. I'm already getting tired of living in the country. If it were meant for me to live on this farm to plant, then yes. But I hope that God will yet help me, I will have land to plant. I will have the life that I hope to have. (JESUS, 1998, p. 144).

No capítulo anterior de Diário de Bitita, encontramos uma estrutura que pode produzir no leitor que lê o livro apenas em inglês o entendimento de que Carolina possuía um pensamento feminista. Vejamos como as mudanças estruturais abalam o sentido da obra:

Jurei nunca mais ser pajem por que na convivência aprendemos amar as crianças. Mas a Nina morreu./ Eu não tinha roupas para vestir. Escrevi um bilhete para a dona Maria Amélia pedindo-lhe os seus vestidos usados./ Ela deu-os escrevi o bilhete com a convicção que ela não ia negar./ Quando gosto de uma pessoa, gosto de vê-la todos os dias (...)

(JESUS, 1986, p. 187).

No capítulo traduzido temos uma injunção feminista na utilização apenas do pronome pessoal "her" no seguinte trecho: 
I swore never again to be a nurse because, through intimacy, we learn to love the children. But Nilza died./ I didn't have any clothes to wear. I wrote a note to Dona Maria Amelia, asking her for her used dresses. She gave me them. I wrote the note with confidence that she wouldn't say no./ When I like a person, I like to see her every day (...)

(JESUS, 1998, p. 140).

Como é sabido, a estrutura da língua portuguesa exige que o nome concorde com o pronome, no caso da frase "Quando gosto de uma pessoa ,gosto de vê'la' todos os dias"; a palavra "pessoa" tem a função de pronome. Nesta frase, o pronome pessoal oblíquo "la" refere-se a tal pessoa. O "la", na verdade, não concorda com "mulher" como demonstra a tradução inglesa, mas concorda com "pessoa", feminino de um pronome em língua portuguesa. Esta pessoa pode ser um homem ou uma mulher. Carolina gosta do ser humano no sentido genérico da palavra, neutro no masculino, e gosta também desta pessoa sobre a qual ela fala que é uma mulher. Se esta tradução primasse pelo tom impessoal da fala de Carolina deveria ser traduzida como "When I like a person, I like to see him/ her every day (...)". Como no inglês não existe essa precisão de concordância de nome a pronome que acompanha a frase, "a person" do inglês (uma pessoa), pode ser do gênero masculino ou feminino. A escolha das tradutoras por "her" faz Carolina pode passar para o leitor a imagem de uma autora feminista. Ao optar aqui por imitar a estrutura do português para exprimir a mesma ideia, a estrutura do inglês exclui ao mesmo tempo o amor que Carolina demonstra pelas pessoas em geral.

À guisa de arremate, gostaríamos de lembrar que o melhor texto traduzido será aquele que conseguir estabelecer uma relação mútua entra a língua-mãe e a língua-alvo, e este processo torna-se um elemento primordial no ato tradutório, principalmente nos dias de hoje. O melhor tradutor ou a melhor tradutora será aquele(a) que consegue realizar sua obra com o mínimo de perdas possível, seja quanto à forma, seja quanto ao conteúdo. Desta maneira, constatamos que quanto menos perdas há na tradução, mais ela tende a ganhar. No caso da tradução de textos literários, ao qual se aplica este estudo, verificamos que como texto artístico, a questão da oralidade e da escrita compósita de Carolina Maria de Jesus tem um peso que não pode passar despercebido ao tradutor, sob pena de agredir o sentido da obra, como tivemos oportunidade de observar pelos vários exemplos dados ao longo deste trabalho. Neste sentido, gostaríamos de ressaltar que cabe às profissionais da tradução aqui estudadas, com o poder autoral que exercem 
e sob a responsabilidade que isto implica, organizar traduções mais abalizadas, procurando inteirar-se da idiossincrasia do(a) autor(a) traduzido(a), a fim de que, estando o mais próximo possível do texto original, não provoquem interferências da sua cultura e da sua subjetividade na obra traduzida.

Para finalizar, gostaríamos de dizer que com esse texto sobre uma das traduções da obra de Carolina, procuramos apontar alguns problemas de ordem interpretativa, sem a intenção de propor um novo texto, mas sim de desvelar as implicações que surgem nesse processo de reescrita. Sejam de ordem cultural, ideológica ou linguística, elas existem e, como pudemos ver, não separam a língua do discurso na dinâmica de construção da comunicabilidade literária.

\begin{abstract}
This article endeavors to establish a comparative study between the Brazilian version of Bitita's diary, by Carolina Maria de Jesus, and its translation into American English done by Emmanuelle Oliveira and Beth Joan Vinkler. The analyzed texts have their ground in the original French edition, first posthumous version published by the journalist and editor A. M. Métaillié, who had access to the manuscripts before Carolina's death and published them in 1982. The novel would come to be published in Brazil in 1986, four years past the first European edition, occasion in which The Nova Fronteira Co. acquired the rights to publish it in Portuguese. Our aim here is to observe in what measure the translators' subjectivity produced sense effects and in what way these possible interferences might be able to affect the reader. We yet seek to reflect in what manner the changes made by them would act upon the reader in the absorption of the new senses generated by retextualization. To this end, we base our research in the Works by Rosemary Arrojo; Jacqueline Authier-Revuz; Rodrigues; Venuti (2002); Neuza Gonçalves Travaglia, Paul Ricoeur and Germana Souza.
\end{abstract}

Key-words: Carolina Maria de Jesus. Translation. Intervention. Subjectivity

\title{
Referências:
}

AUTHIER-REVUZ, Jacqueline. Palavras incertas: não coincidências do dizer. Campinas, 1998.

ARROJO, Rosemary. Oficina de tradução: a teoria na prática. São Paulo: Editora Ática, 1986. 
CORACINI, Maria José. A celebração do outro: arquivo, memória e identidade. Línguas (materna e estrangeira), plurilinguismo e tradução. Campinas, SP: Mercado das Letras, 2007.

DERRIDA, Jacques. What is a 'relevant' translation? Tradução de Lawrence Venuti. In: Critical Inquire, n. 27. The University of Chigago Press, 2000.

FERNANDEZ, Raffaella Andréa. Carolina Maria de Jesus, uma poética de resíduos. (Dissertação Mestrado em Letras Estudos Literários Assis). Universidade Estadual Paulista Júlio de Mesquita Filho, UNESP, 2006.

FERREIRA, Eduardo. "Sobre o prefácio à tradução de Paul Ricoeur: O instigante comentário de Patrícia Lavelle sobre o texto do filósofo francês" In: Rascunho: o Jornal de Literatura do Brasil. No 172, Agosto de 2014. Disponível em: http:// rascunho.gazetadopovo.com.br/wp-content/uploads/2014/07/Capa_172.jpg Acesso em: 18/08/2014

FISH, Stanley. Is there a text in this class? The authority of interpretive Communities. Cambridge: Harvard University Press, 1980

GOMES, Angela Castro (Org.). Escrita de si, escrita da história. Rio de Janeiro: Editora FGV, 2004.

JESUS, Carolina Maria de. Diário de Bitita. Rio de Janeiro: Nova Fronteira, 1986.

JESUS, Carolina Maria de. Journal de Bitita. Paris: A.M. Métalié, 1980.

JESUS, Carolina Maria. Bitita's diary: the childhood memoirs of Carolina Maria de Jesus. New York: M.E. Sharpe, 1998.

QUINE, Willard Van Orman. Word \& object. Massachusetts: The Library of Congress, [1960] 2013.

LAVELLE, Patrícia. Prefácio. In RICOEUR, Paul, Sobre a tradução. Belo Horizonte: Editora UFMG, 2001.

RICOEUR, Paul. Sobre a tradução. Trad. Patrícia Ravelle. Belo Horizonte: Editora da UFMG, 2011.

SILVA, Mário A. M. $\boldsymbol{A}$ descoberta do insólito: Carolina Maria de Jesus e a imprensa brasileira (1960-1977). [S.I.] Afro-Hispanic Review: Vol.2. Number 2, 2010. Disponível em: <http://www.afrohispanicreview.com/2011/08/vol-29number-2-fall-2010.html>. Acesso em 18 de abr. 2012, 15:20:10. 
SOUZA, H. P. Germana. A tradução francesa da linguagem compósita de Carolina Maria de Jesus. Cadernos de Tradução: Vol.2. número 28, 2011. Disponível em: $<$ http://www.periodicos.ufsc.br/index.php/traducao/article/vie21757968.2011v2n 28p121>Acesso em 15 de fev. 2012, 10:40:15.

STEINER, George. After babel: aspects of language and translation. Oxford, Oxford University Press, 1975.

TRAVAGLIA, Neuza Gonçalves. Tradução retextualização: a tradução numa perspectiva textual. Uberlândia: EDUFU, 2003. 
ENTREVISTAS 
